\title{
Kompozit Malzemelerin Delme İşleminde İtme Kuvvetinin Taguchi Metodu ile Optimizasyonu ve Regresyon Analizi ile Tahmini
}

\author{
Gökhan BAŞAR ${ }^{1}$, Yusuf FEDAİ ${ }^{*}$, Hediye KIRLI AKIN ${ }^{1}$ \\ ${ }^{1}$ Osmaniye Korkut Ata Üniversitesi, Mühendislik Fakültesi, Endüstri Mühendisliği Bölümü, \\ Osmaniye
}

Geliş tarihi: $27.10 .2020 \quad$ Kabul tarihi: 30.12 .2020

Öz

Cam Elyaf Takviyeli Polimer (CETP) kompozitler, diğer malzemelere göre daha üstün özelliklere sahip olmasından dolayı birçok mühendislik uygulamalarında kullanılmaktadır. Bu kompozitlerin montajında delme işlemi yaygın olarak uygulanmaktadır. CETP malzemelerin delinmesinde; yüksek delik yüzey kalitesi ile minimum deformasyon ve itme kuvveti için delme parametrelerinin belirlenmesi oldukça önemlidir. Bu yüzden, delme işlemi sırasında oluşan delik yüzeyi hasarını en aza indirmek için optimum delme koşulları belirlenmelidir. $\mathrm{Bu}$ çalışmada, delme işleminde itme kuvveti Taguchi Metodu kullanılarak optimize edilmiştir. Ayrıca, itme kuvvetinin tahminine yönelik matematiksel modeller geliştirilmiştir. Delme parametrelerinin itme kuvveti üzerindeki etki oranları varyans analizi ile belirlenmiştir. Varyans analizine göre itme kuvveti üzerindeki en etkili parametrenin ilerleme olduğu görülmüştür. İtme kuvvetini tahmin etmek için Taguchi Metodu, birinci ve ikinci dereceden regresyon modelleri kullanılmıştır. Elde edilen sonuçlar ile deney sonuçları karşılaştııılmıştır. Ayrıca, üç boyutlu grafikler incelendiğinde, \% çok duvarlı karbon nanotüp oranı ve kesme hızı arttıkça itme kuvvetinin azaldığını ve ilerleme arttıkça itme kuvvetinin arttığını göstermiş̧ir.

Anahtar Kelimeler: Delme işlemi, CETP, İtme kuvveti, Taguchi Metodu, Regresyon analizi, Varyans analizi, Çok duvarlı karbon nanotüp

\section{Optimization of Thrust Force with Taguchi Method and Estimation by Regression Analysis in Drilling of Composite Materials}

\begin{abstract}
Glass Fibre Reinforced Plastic (GFRP) composites are used in many engineering applications due to their superior properties than other materials. Drilling is widely used in the assembly of these composites. It is very important to determine the drilling parameters for high hole surface quality, minimum deformation
\end{abstract}

*Sorumlu yazar (Corresponding author): Yusuf FEDAİ, yusuffedai@osmaniye.edu.tr 

ile Tahmini

and thrust force when drilling GFRP materials. Therefore, optimum drilling conditions must be determined to minimize hole surface damage during the drilling process. In this study, the thrust force in the drilling process was optimized by using the Taguchi Method. In addition, mathematical models have been developed to predict thrust force. The contribution rates of the drilling parameters on the thrust force were determined by analysis of variance. According to variance analysis, it was seen that the most effective parameter on the thrust force was the feed rate. Taguchi Method, first and second order regression models were used to estimate thrust force. The results obtained were compared with the experimental results. Among the developed models, the model with the highest prediction ability is the second-order regression model with the highest $\mathrm{R}^{2}$ value $(98.14 \%)$ and the lowest average absolute error value $(1.86 \%)$. When the three-dimensional graphs are examined, it has been shown that the thrust force decreases as the amount of multi-walled carbon nanotubes and the cutting speed increases, and the thrust force increases as the amount of feed increases. Additionally, when three-dimensional graphs are examined, it has been shown that as the \% multi-walled carbon nanotube ratio and cutting spees increases, the thrust force decreases and the thrust force increases as the feed rate increases.

Keywords: Drilling process, GFRP, Thrust force, Taguchi Method, Regression Analysis, Variance Analysis, Multi wall carbon nanotube

\section{GİRIŞ}

Cam Elyaf Takviyeli Polimer (CETP) kompozitler malzemeler, yüksek özgül dayanım, sertlik ve tokluk, hafiflik, üstün korozyon direnci ve düşük termal genleşme özelliklerinden dolayı otomotiv, uzay ve havacılık, denizcilik, kimya ve nükleer endüstrisinde oldukça geniş bir kullanım alanına sahiptir [1-3]. Son zamanlarda, kompozit malzemelerin üretiminde epoksiye nanoboyutlu takviye elemanlarının eklendiği ve nanopartikül takviyeli kompozit malzemelerin üretiminde hızlı bir artış olduğu görülmektedir. Örneğin, karbon nanotüpler, grafen ve nanofiberlerin takviye malzemesi olarak kullanımı kompozit malzemelerde gittikçe artmaktadır. Çünkü bu takviye elemanları, daha iyi yapısal ve fonksiyonel özelliklere ve geniş kullanım alanlarına sahiptirler [4]. Nano partikül takviye elemanına bağlı olarak kompozit malzemelerin mekanik, elektriksel ve termal özelliklerini etkileyebilir. Karbon nanotüp takviyeli kompozit malzemeler, özellikle otomobil endüstrisinde ticari başarı elde etmişlerdir [5,6]. CETP kompozitler endüstride yaygın olarak, arzu edilen geometrik ve boyutsal toleranslara getirmek için talaşlı imalat yöntemleriyle veya birleştirme (yapıştırma) işlemleriyle kullanılmaktadırlar [1-3]. Talaşlı imalat yöntemleri içerisinde tornalama, frezeleme, delme, taşlama vb. en çok kullanılan yöntemlerdendir. CETP kompozitler nihai şekline yakın üretilseler de montaj işlemleri esnasında istenilen toleranslara ulaşılabilmesi için talaşlı imalat yöntemlerinden biri olan delme işlemine ihtiyaç duyulmaktadır [2,7]. $\mathrm{Bu}$ malzemelerin delinmesi sonucunda; tabakalar arası çatlak ve ayrışma, elyaf çekmesi ve kopması, fiber/reçine ayrılması, mikro çatlaklar, delik bölgesinde oluşan deformasyon, gerilme yoğunlaşması ve delik yüzey kalitesi vb. hatalar ile karşılaşılabilmektedir $[1,8]$. $\mathrm{Bu}$ malzemelerin delinmesinde karşılaşılan en büyük hata delik giriş ve çıkışlarında oluşan deformasyondur. Deformasyon, malzemenin bütünlüğünü bozarak dayanımını azaltmaktadır. Deformasyonun oluşmasını engellemek mümkün olmadığı için en aza indirmek için birtakım bilimsel çalışmalar yapılmış ve hala yapılmaya devam etmektedir [3]. Delme işleminde meydana gelen bu hatalardan dolayı birçok parça üretim esnasında ıskartaya ayrılmaktadır. Örneğin, uçak endüstrisinde bu hatalardan dolayı parçaların \%60'1 kabul edilebilir tolerans değerlerinin dışında kalmaktadır [9]. Literatürde yapılan çalışmalarda deliğin yüzey kalitesinin, delme parametreleri, takım malzemesinin cinsi, kesici takımın geometrisi ve itme kuvvetine bağlı olduğu belirtilmiştir [2,10]. Şekil 1'de kompozit malzemenin delinmesi sırasında oluşan itme 
kuvveti, kesici takım şematik olarak verilmiştir. CETP kompozit malzemelerin delme işleminde, yüksek delik yüzey kalitesi, en az deformasyon ve en küçük itme kuvveti için delme parametrelerinin tespit edilmesi büyük öneme sahiptir. Yüksek kaliteli delme için optimum delme parametreleri belirlenmelidir [11]. Tabakalı kompozit malzemelerin delinmesinde meydana gelen en önemli hatanın tabaka ayrılması olduğu ve bunun esas nedenin de itme kuvveti olduğu tespit edilmiştir [12].

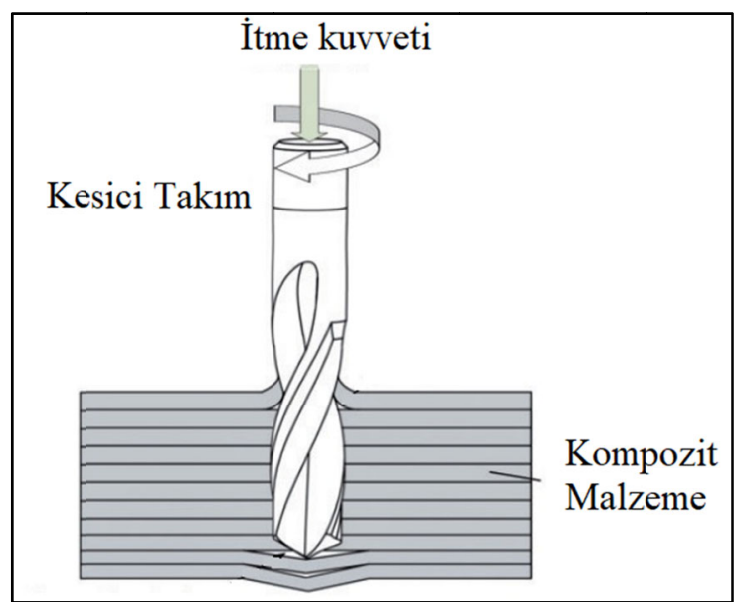

Şekil 1. Kompozit malzemeyi delme sırasında oluşan itme kuvveti ve kesici takımın şematik resmi [13]

Literatürde yapılan çalışmalar incelendiğinde; Unal [14] CETP malzemesinin delinmesinde uç açısı, devir sayısı ve ilerlemenin itme kuvveti ve sıcaklık üzerindeki etkilerini araştırmak için varyans analiz (ANOVA) yöntemini kullanmıştır. Delme deneyleri, kaplamasız HSS matkaplar ile gerçekleştirilmiş ve kesme sıvısı kullanılmamıştır. ANOVA sonuçları, itme kuvvetini en fazla ilerlemenin etkilediği, sıcaklığı ise en fazla uç açısının etkilediği görülmüştür. Sing ve Kumar [15] CETP nanokompozitlerin delinmesinde, delme parametrelerinin yüzey pürüzlülüğü ve delaminasyon üzerindeki etkilerini araştırmışlardır. Delme parametreleri olarak; devir sayısı, ilerleme, matkap çapı ve ağılıkça \% ÇDKNT oranı seçilmiştir. Tepki Yüzeyi Metodolojisini kullanarak yüzey pürüzlülüğü ve delaminasyon katsayısı için matematiksel modeller geliştirmişlerdir. Delaminasyon katsayısı üzerindeki en önemli parametrenin matkap çapı ve yüzey pürüzlülüğü üzerindeki en önemli parametrenin \% ÇDKNT oranı olduğu ANOVA ile tespit edilmiştir. Vankanti ve Ganta [16] CETP kompozitlerin delinmesinde Taguchi Metodunu kullanarak optimum delme parametrelerini belirlemişlerdir. Kesme hızı, ilerleme, uç açısı ve uç kenar genişliği delme parametreleri olarak kullanılmıştır. Ayrıca, delme parametrelerinin itme kuvveti, tork, yüzey pürüzlülüğü ve dairesellik üzerindeki etki oranları ANOVA ile belirlenmiştir. Vyas ve arkadaşları [17] CETP delinmesinde delme parametrelerinin itme kuvveti ve dairesellik üzerindeki etkilerini araştırmışlardır. İtme kuvveti ve dairesellik için optimum delme parametreleri belirlemişlerdir. ANOVA ile delme parametrelerinin katkı oranları tespit edilmiştir. Ayrıca, itme kuvveti ve dairesellik için regresyon denklemleri elde etmişlerdir.

Literatür çalışmaları incelendiğinde, genellikle deneysel tasarım yöntemleri kullanılarak optimizasyon ve modelleme yapılmıştır. $\mathrm{Bu}$ çalışmadaki amaç ise hem optimizasyon ve modelleme hem de farklı modellerin tahmin değerlerinin karşılaştırılmasıdır.

$\mathrm{Bu}$ çalışmada, takviyesiz ve ÇDKNT takviyeli CETP kompozit malzemelerin delinmesinde delme parametrelerinin itme kuvveti üzerindeki etkileri Taguchi Metodu ve Varyans Analizi (ANOVA) ile belirlenmiştir. Ayrıca, birinci ve ikinci dereceden regresyon analizi yapılarak itme kuvvetinin tahmini için matematiksel modeller geliştirilmiştir. Deney sonuçları ile tahmin modellerinin sonuçları karşılaştırılmış ve yorumlanmıştır.

\section{MATERYAL VE METOT}

\subsection{Delme parametreleri ve Kullanılan Cihazlar}

$\mathrm{Bu}$ çalışmada kullanılan CETP kompozit malzemeler, İnovatif Malzeme Teknolojileri San. ve Tic. Ltd. Şti. firması tarafından üretilmiştir. 
Kompozit Malzemeleri Delme Isşleminde İtme Kuvvetinin Taguchi Metodu ile Optimizasyonu ve Regresyon Analizi ile Tahmini

Başar ve arkadaşları [18] tarafindan yapılan çalışmada, kompozit malzemelerin üretimi hakkında detaylı bilgi verilmiştir. Takviyesiz, $\% 0,5$ ve \%1 ÇDKNT takviyeli CETP kompozit malzemelerin delinmesi işleminde delme parametrelerinin itme kuvveti üzerindeki etkileri incelenmiştir. Delme deneyleri için Johnford VMC 850 marka CNC dik işleme merkezi kullanılmıştır. Delme işlemini gerçekleştirmek için $\varnothing 8 \mathrm{~mm}$ kaplamasız karbür kesici takımları kullanılmıştır. Ağırlıkça \% ÇDKNT oranı, kesme hızı ve ilerleme delme parametreleri olarak seçilmiştir. Kontrol faktörleri ve seviyeleri Çizelge 1'de verilmiştir. Deneyler, tam faktöriyel deney tasarımına göre gerçekleştirilmiştir.
CNC dik işleme merkezinin tablasına yerleştirilmiş olan Kistler 9257B tipi dinamometre kullanılarak itme kuvveti (Fz) ölçülmüştür (Şekil 2). Kistler DynoWare yazılımı sayesinde itme kuvveti verileri bilgisayar ortamında kayıt altınıa alınmıştır. Şekil 3 (a) da deney sirasinda elde edilen kesme kuvvet grafiği verilmiştir (Deney 6). Grafik incelendiğinde, delme sırasında oluşan itme kuvveti z ekseninde Fz ile gösterilmiştir (Şekil 3 (b)). Yatay düzlemde meydana gelen $\mathrm{x}$ ve $\mathrm{y}$ eksenlerinde oluşan kuvvetler ise sırasıyla Fx ve Fy kuvvetleridir (Şekil 3 (b)). Fx ve Fy kuvvetleri çok küçük olduğu için dikkate alınmamıştır.

Çizelge 1. Delme parametreleri ve seviyeleri

\begin{tabular}{|l|c|c|c|c|}
\hline \multirow{2}{*}{ Delme parametreleri } & \multirow{2}{*}{ Sembol } & \multicolumn{3}{|c|}{ Seviyeler } \\
\cline { 3 - 5 } & & $\mathbf{1}$ & $\mathbf{2}$ & $\mathbf{3}$ \\
\hline ÇDKNT oranı (\%) & $\mathrm{A}$ & 0 & 0,5 & 1 \\
\hline Kesme hızı (m/dk) & $\mathrm{B}$ & 25 & 50 & 75 \\
\hline İlerleme (mm/dev) & $\mathrm{C}$ & 0,10 & 0,15 & 0,20 \\
\hline
\end{tabular}

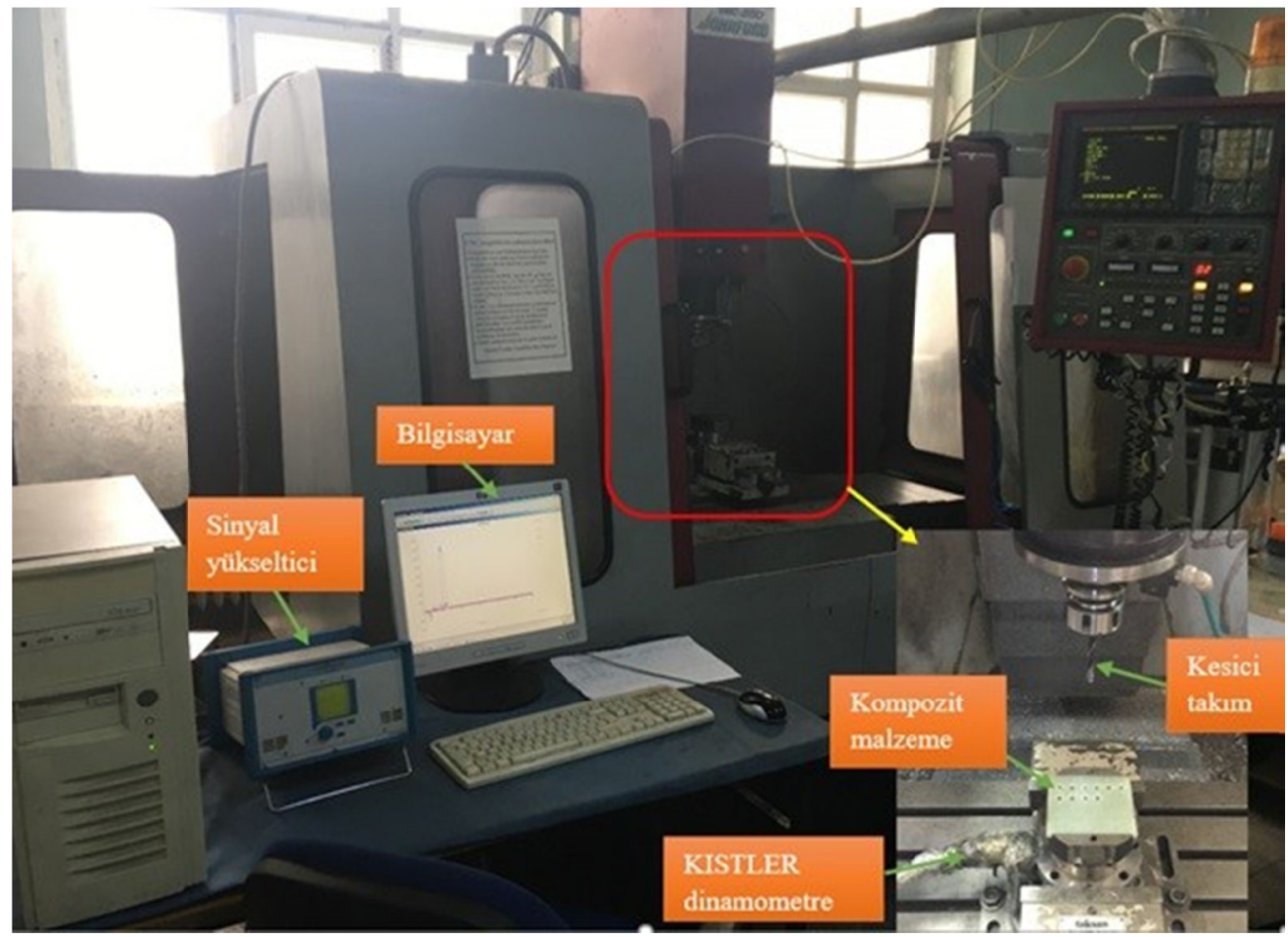

Şekil 2. Delme işleminde kullanılan deney düzeneği 


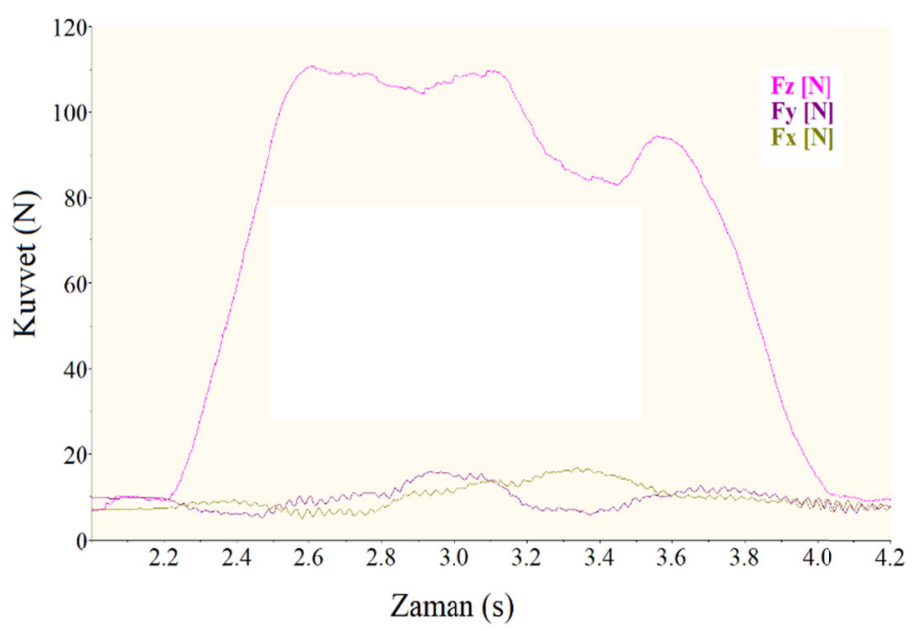

(a)

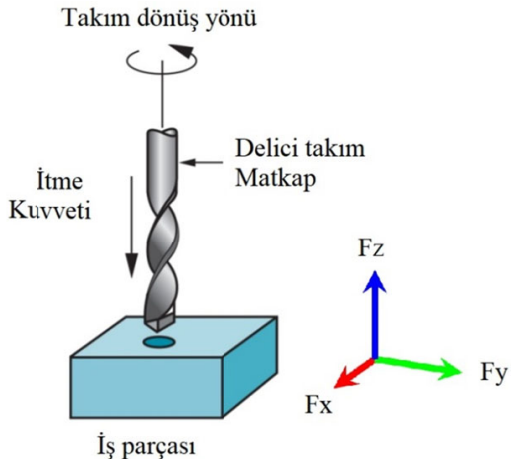

(b)

Şekil 3. Delme sırasında meydana gelen kesme kuvvetleri örneğ

\subsection{Deney Tasarımı ve Analiz}

Taguchi Metodu, bilimsel çalışmalarda en sık kullanılan deney tasarım metotları arasındadır. Deney tasarımı ile bir ürün veya proses tasarımında karşı karşıya kalınan problemlerde en iyi çözümlerin sağlandığı şartları oluşturabilmek için kalite karakteristiği tespit edilerek bu karakteristiği etkileyen faktörler araştırılmaktadır. $\mathrm{Bu}$ amaçla kalite karakteristiği üzerinde etkili olduğu düşünülen kontrol faktörler ve bu kontrol faktörlerin farklı seviyeleri seçilerek bir deney tasarımı oluşturulur. Oluşturulan deney tasarımına göre kalite karakteristiğin performans değeri ölçülmektedir [19].

Taguchi, deney tasarımına göre yapılan deneylerde dikkate almadığı kontrol edilemeyen faktörlerin deney üzerindeki etkilerini azaltmak amacıyla, Sinyal/Gürültü (S/N) oranı ortaya koymuştur. Kontrol faktörlerinin ve seviyelerinin performans karakteristiğini ölçmek için amaç fonksiyon değerlerini $\mathrm{S} / \mathrm{N}$ oranına dönüştürür. $\mathrm{S} / \mathrm{N}$ oranlarının hesaplanmasında; kalite karakteristiğin amacına göre "en küçük en iyi, nominal en iyi, en büyük en iyi” üç farklı formül kullanılır [20,21]. Herhangi bir deneyin amaç fonksiyonuna bakılmaksızın sonuç için en yüksek $\mathrm{S} / \mathrm{N}$ oranına ulaşmaktır [22]. Bu çalışmadla, $\mathrm{S} / \mathrm{N}$ oranlarının belirlenmesinde, delme işlemnlerinin verimliliği açısından itme kuvvetinin en küçük olması istenildiği için Eşitlik 1'de verilen 'En küçük en iyi” prensibine karşılık gelen formül kullanılmıştır. Ayrica, delme parametrelerinin istatistiksel olarak önemini ve kontrol faktörlerinin kalite karakteristiği üzerindeki katk1 oranlarını tespit etmek amaciyla varyans analizi (ANOVA) uygulanmıştır [23] (Eşitlik1).

$$
\frac{\mathrm{S}}{\mathrm{N}}=-10 \log \left(\frac{1}{\mathrm{n}} \sum_{\mathrm{i}=1}^{\mathrm{n}} \mathrm{y}_{\mathrm{i}}^{2}\right)
$$

Burada, n: gözlemlenen değer sayısı ve y: gözlemlenen veridir [20,24].

Regresyon analizi, bağımlı değişkendeki değişimi bağımsız değişkenler ile açıklamak için kurulan matematiksel bir modeldir [25]. Geliştirilen modellerin başarısını ölçmek için belirtme katsayısı $\left(\mathrm{R}^{2}\right)$ kullanılır. $\mathrm{Bu}$ katsayı, bağımsız değişkenlerin bağımlı değişkeni açıklama oranıdır. 0 ila 1 arasında olup 1'e ne kadar yakın olursa bağımlı değişkendeki değişimin büyük bir kısmı bağımsız değişken tarafından açılanabildiğini ifade etmektedir [26,27]. 
Kompozit Malzemeleri Delme Işsleminde İtme Kuvvetinin Taguchi Metodu ile Optimizasyonu ve Regresyon Analizi ile Tahmini

\section{DENEYSEL SONUÇLAR VE oranı Çizelgesi veya grafiği kullanılarak ANALIZI belirlenmiştir.}

\subsection{Taguchi Metodu}

Delme deneyleri sırasında meydana gelen itme kuvveti $\left(F_{z}\right)$ için “en küçük en iyi” amaç fonksiyonu kullanılmış ve S/N oranları Eşitlik 1 kullanılarak hesaplanmıştır (Çizelge 2).

Kontrol faktörlerinin en uygun seviyeleri ve kalite karakteristiği üzerinde en etkili faktörün tespit

Çizelge 3'te itme kuvvetinin ortalama S/N oranları ve Şekil 4'de itme kuvvetinin S/N oranları için ana etki grafikleri verilmiştir. Şekil 4'deki ana etki grafikleri ve Çizelge 3'teki $\mathrm{S} / \mathrm{N}$ oranlarından optimum kontrol faktörlerinin seviyeleri A3B3C1 olduğu tespit edilmiştir. Buna göre; itme kuvveti üzerindeki kontrol faktörlerinin etki sırası ilerleme, kesme hızı ve \% ÇDKNT oranı olarak belirlenmiştir. edilmesinde Taguchi Metodu ile oluşturulan $\mathrm{S} / \mathrm{N}$

Çizelge 2. İtme kuvveti için deney sonuçları ve $\mathrm{S} / \mathrm{N}$ değerleri

\begin{tabular}{|c|c|c|c|c|c|}
\hline $\begin{array}{c}\text { Deney } \\
\text { Sirası }\end{array}$ & $\begin{array}{c}\text { CDKNT } \\
\text { oranı }(\mathbf{\%})\end{array}$ & $\begin{array}{c}\text { Kesme hızı } \\
(\mathbf{m} / \mathbf{d k})\end{array}$ & $\begin{array}{c}\text { Ilerleme } \\
(\mathbf{m m} / \mathbf{d e v})\end{array}$ & $\boldsymbol{F}_{\mathbf{z}}[\mathbf{N}]$ & $\begin{array}{c}\boldsymbol{F}_{\mathbf{z}}(\mathbf{S} / \mathbf{N}) \\
{[\mathbf{d B}]}\end{array}$ \\
\hline 1 & 0 & 25 & 0,10 & 50,66 & $-34,0933$ \\
\hline 2 & 0 & 25 & 0,15 & 63,38 & $-36,0390$ \\
\hline 3 & 0 & 25 & 0,20 & 82,56 & $-38,3354$ \\
\hline 4 & 0 & 50 & 0,10 & 49,23 & $-33,8446$ \\
\hline 5 & 0 & 50 & 0,15 & 61,94 & $-35,8394$ \\
\hline 6 & 0 & 50 & 0,20 & 76,04 & $-37,6208$ \\
\hline 7 & 0 & 75 & 0,10 & 46,3 & $-33,3116$ \\
\hline 8 & 0 & 75 & 0,15 & 61,98 & $-35,8450$ \\
\hline 9 & 0 & 75 & 0,20 & 71,86 & $-37,1297$ \\
\hline 10 & 0,5 & 25 & 0,10 & 46,74 & $-33,3938$ \\
\hline 11 & 0,5 & 25 & 0,15 & 62,95 & $-35,9799$ \\
\hline 12 & 0,5 & 25 & 0,20 & 74,63 & $-37,4583$ \\
\hline 13 & 0,5 & 50 & 0,10 & 44,43 & $-32,9535$ \\
\hline 14 & 0,5 & 50 & 0,15 & 56,72 & $-35,0747$ \\
\hline 15 & 0,5 & 50 & 0,20 & 67,2 & $-36,5474$ \\
\hline 16 & 0,5 & 75 & 0,10 & 44,24 & $-32,9163$ \\
\hline 17 & 0,5 & 75 & 0,15 & 54,18 & $-34,6768$ \\
\hline 18 & 0,5 & 75 & 0,20 & 65,65 & $-36,3447$ \\
\hline 19 & 1 & 25 & 0,10 & 48,33 & $-33,6843$ \\
\hline 20 & 1 & 25 & 0,15 & 59,24 & $-35,4523$ \\
\hline 21 & 1 & 25 & 0,20 & 75,01 & $-37,5024$ \\
\hline 22 & 1 & 50 & 0,10 & 45,01 & $-33,0662$ \\
\hline 23 & 1 & 50 & 0,15 & 55,86 & $-34,9420$ \\
\hline 24 & 1 & 50 & 0,20 & 68,19 & $-36,6744$ \\
\hline 25 & 1 & 75 & 0,10 & 39,3 & $-31,8879$ \\
\hline 26 & 1 & 75 & 0,15 & 48 & $-33,6248$ \\
\hline 27 & 1 & 75 & 0,20 & 59,75 & $-35,5268$ \\
\hline & & & & & \\
\hline
\end{tabular}


Seçilen kalite karakteristiğine kontrol faktörlerinin etkilerini tespit etmek için tam faktöriyel deney tasarımdaki her bir deney için \%95 güven aralığında varyans analizi (ANOVA) uygulanmıştır. İtme kuvveti için yapılan ANOVA sonuçları Çizelge 4'de verilmiştir. Çizelge 4 incelendiğinde, itme kuvveti üzerinde en etkili faktör \%81,17 katkı oranıla ilerleme olmuştur. İlerlemeyi $\% 8,26$ ve $\% 7,18$ katk1 oranları ile sırasıyla kesme hızı ve \% ÇDKNT oranı takip etmiştir.
Çizelge 3. İtme kuvvetinin ortalama $\mathrm{S} / \mathrm{N}$ oranları için kontrol faktörlerinin önem sırası

\begin{tabular}{|c|c|c|c|}
\hline Seviye & $\mathbf{A}$ & $\mathbf{B}$ & $\mathbf{C}$ \\
\hline 1 & $-35,78$ & $-35,77$ & $-33,24$ \\
\hline 2 & $-35,04$ & $-35,17$ & $-35,27$ \\
\hline 3 & $-34,71$ & $-34,58$ & $-37,02$ \\
\hline Fark & 1,08 & 1,19 & 3,78 \\
\hline Önem sirası & $\mathbf{3}$ & $\mathbf{2}$ & $\mathbf{1}$ \\
\hline
\end{tabular}

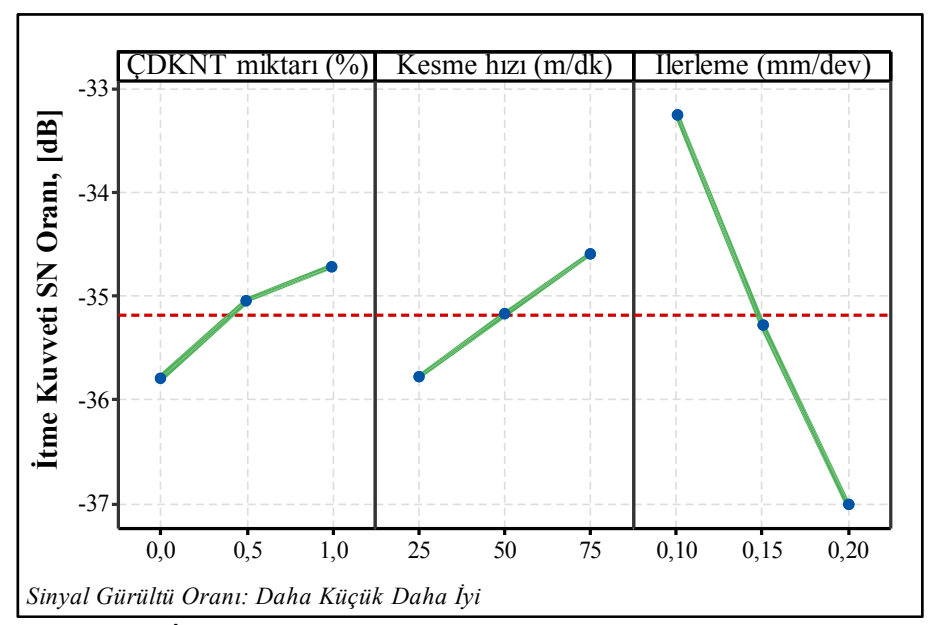

Şekil 4. İtme kuvvetinin $\mathrm{S} / \mathrm{N}$ oranları için ana etki grafikleri

Çizelge 4. İtmek kuvveti için varyans analizi

\begin{tabular}{|c|c|c|c|c|c|c|}
\hline Kaynak & $\begin{array}{c}\text { Serbestlik } \\
\text { Derecesi }\end{array}$ & $\begin{array}{c}\text { Kareler } \\
\text { Toplamı }\end{array}$ & $\begin{array}{c}\text { Kareler } \\
\text { Ortalaması }\end{array}$ & F değeri & P değeri & $\begin{array}{c}\text { Katkı oranı } \\
(\%)\end{array}$ \\
\hline A & 2 & 252,4 & 126,18 & 21,11 & $\mathbf{0 , 0 0}$ & 7,18 \\
\hline B & 2 & 290,5 & 145,24 & 24,30 & $\mathbf{0 , 0 0}$ & 8,26 \\
\hline C & 2 & 2854,7 & 1427,36 & 238,78 & $\mathbf{0 , 0 0}$ & 81,17 \\
\hline Hata & 20 & 119,6 & 5,98 & & & 3,40 \\
\hline Toplam & 26 & 3517,1 & \multicolumn{7}{|c|}{ Model Özeti } \\
\hline \multicolumn{7}{|c|}{$\mathrm{R}^{2}($ adj): \% 95,58 } \\
\hline
\end{tabular}

Kalite karakteristiği ve kontrol faktörleri arasındaki değişime ilişkin üç boyutlu yüzey grafikleri Şekil 5 (a-c)'de verilmiştir. Şekil 5 (a)'da ilerleme ve kesme hızının itme kuvveti üzerindeki etkileri gösterilmiştir. Buradan ilerlemenin azalması ile itme kuvvetinde büyük oranda bir azalma görülmüştür. İlerleme, kesme alanı yüksekliği ve itme kuvveti arasında bir ilişki vardır. İlerlemenin artmasına bağlı olarak kesme alanı yüksekliği artmaktadır. Kesme alanı yüksekliğinin artması da itme kuvvetinin yükselmesine neden olmaktadır [28]. Çalışmanın sonuçları literatür ile uyum içerisindedir [18]. Ayrıca, kesme hızı arttıkça itme kuvvetinde bir miktar azalma görülmektedir. Talaş kaldırma sırasında kesici takım ve iş parçası arasındaki 
sürtünmeden dolayı sıcaklık oluşmaktadır. Kesme hızının artması ile kesme bölgesindeki sıcaklık artar ve kompozit malzemenin yumuşamasına neden olur. Böylece, kesme hızının artması ile itme kuvvetinde bir azalma meydana gelmektedir $[29,30]$. Şekil 5 (b)'de \% ÇDKNT oranı ve kesme hızının itme kuvveti üzerindeki etkileri gösterilmiştir. \% ÇDKNT oranı ve kesme hızının birlikte artmasiyla itme kuvvetinde ciddi bir azalma meydana gelmiştir. Kumar ve Sing delme işleminde en düşük itme kuvveti, ağırlıkça \%1,5 ÇDKNT takviyeli karbon elyaf polimer

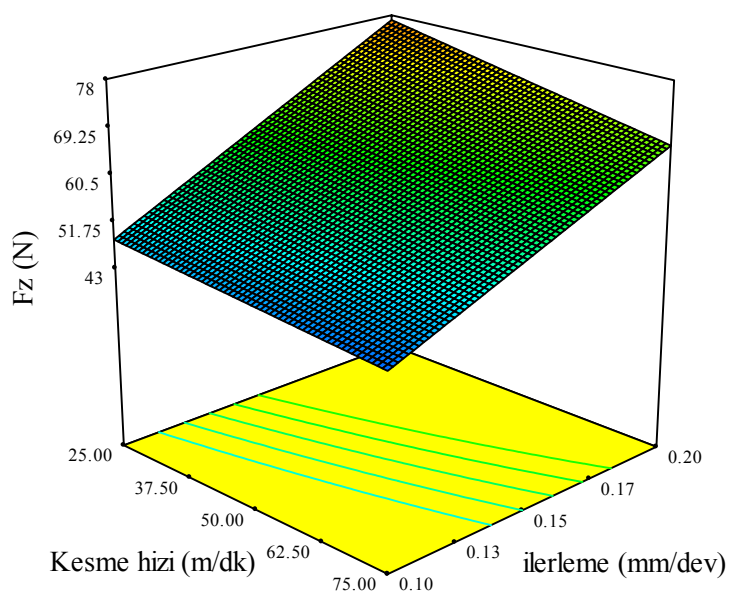

(a) nanokompozit malzemede elde etmişlerdir. Ayrıca, \% ÇDKNT oranının artmasıyla itme kuvvetinin azaldığını tespit etmişlerdir. ÇDKNT takviyesi, takım-talaş arayüzünde yağlama özelliği gösterdiğini ve bu özelliğin delme işlemini kolaylaştırdığını ifade etmişlerdir [31]. Şekil 5 (c)'de ilerleme ve \% ÇDKNT oranının itme kuvveti üzerindeki etkileri gösterilmiştir. İlerlemenin azalması ile itme kuvvetinde göze çarpan bir şekilde azalma görülmüştür. Ayrıca, \% ÇDKNT oranının artması ile itme kuvvetinde bir miktar düşüş meydana gelmiştir.

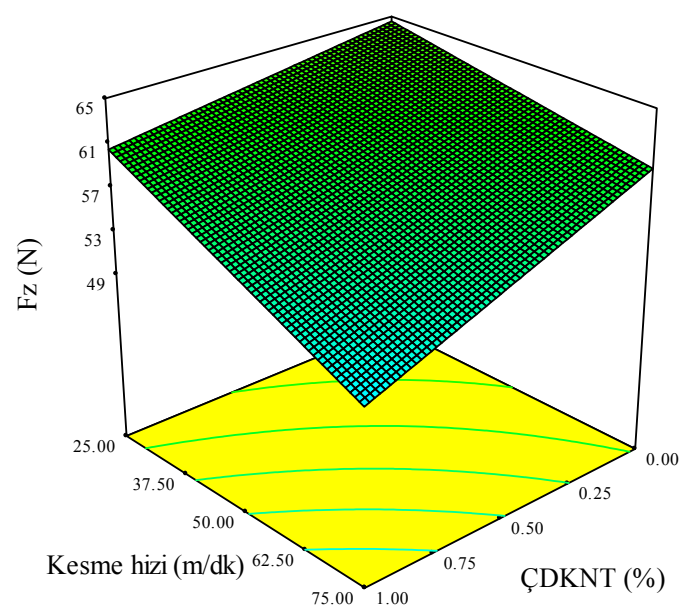

(b)

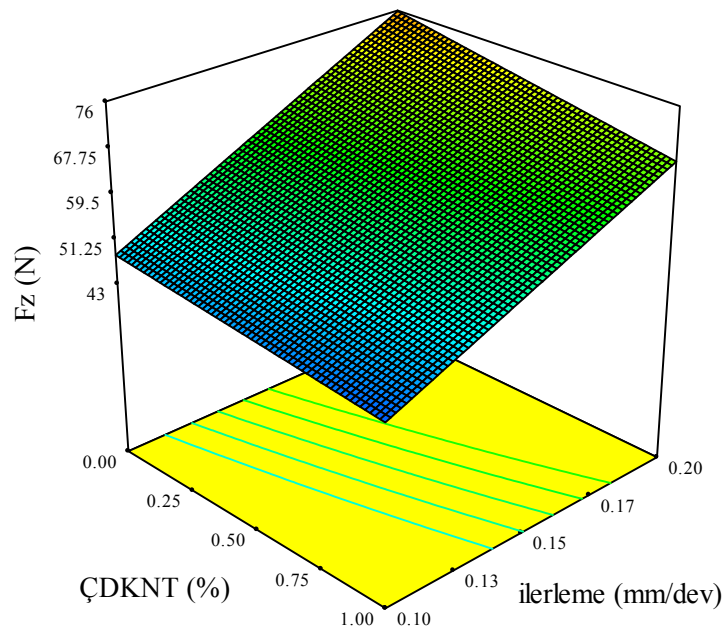

(c)

Şekil 5. Kontrol faktörlerinin kalite karakteristiğine etki grafikleri a) ilerleme ve kesme hızı b) ÇDKNT ve kesme hızı c) İlerleme ve ÇDKNT 


\subsection{Regresyon Analizi}

Kontrol faktörleri ve kalite karakteristiği arasındaki sebep sonuç ilişkisini tespit etmek için regresyon analizleri gerçekleştirilmiştir. İtme kuvvetinin tahmini için Minitab 17 paket programı kullanılmıştır. Birinci ve ikinci dereceden regresyon analizleri yapılarak matematiksel denklemler elde edilmiştir.

\subsubsection{Birinci Dereceden Regresyon Analizi}

CEPT kompozitlerin delinmesinde meydana gelen itme kuvvetinin tahmini için yapılan birinci dereceden regresyon analizi denklemi, Eşitlik 2'de ve denklem katsayıları ise Çizelge 5'te verilmiştir.

$F z=32,37-7,25 A-0,1605 B+251,8 C$

Çizelge 5. Birinci dereceden regresyon analiz katsayıları

\begin{tabular}{|c|c|c|c|c|}
\hline Term & Coef & $\begin{array}{c}\text { SE } \\
\text { Coef }\end{array}$ & $\begin{array}{c}\text { T- } \\
\text { Value }\end{array}$ & $\begin{array}{c}\text { P- } \\
\text { Value }\end{array}$ \\
\hline Constant & 32,37 & 2,20 & 14,71 & $\mathbf{0 , 0 0}$ \\
\hline A & $-7,25$ & 1,15 & $-6,31$ & $\mathbf{0 , 0 0}$ \\
\hline B & $-0,1605$ & 0,0230 & $-6,98$ & $\mathbf{0 , 0 0}$ \\
\hline C & 251,8 & 11,5 & 21,91 & $\mathbf{0 , 0 0}$ \\
\hline \multicolumn{5}{|c|}{ Model Özeti } \\
\hline $\mathrm{R}^{2}:$ & $\% 96,11$ \\
\hline $\mathrm{R}^{2}$ (adj): & $\% 95,61$ \\
\hline $\mathrm{R}^{2}$ (pred): & $\% 94,44$ \\
\hline
\end{tabular}

Regresyon analizinde, $\mathrm{R}^{2}$ belirtme katsayısı 1'e ne kadar yakın olursa modelin o kadar güçlü olduğu anlama gelmektedir. Geliştirilen modelde, $\mathrm{R}^{2}$ \%96,11 olarak hesaplanmıştır. Çizelge 5'te $\mathrm{P}$ anlamlılık değerleri incelendiğinde, kontrol faktörlerinin itme kuvveti üzerinde önemli etkiye sahip olduğu gözlemlenmiştir.

\subsection{2. İkinci Dereceden Regresyon Analizi}

Birinci dereceden regresyon analizi yapılmasının ardından itme kuvvetinin tahmini için ikinci dereceden regresyon analizi yapılmıştır. İkinci dereceden regresyon analizi denklemi,
Eşitlik 3'te ve denklem katsayıları ise Çizelge 6'da verilmiştir.

$$
\begin{aligned}
& F z=20,81-0,39 A+0,044 B+294,4 C+6,48 A^{2}+ \\
& 0,00049 B^{2}+147 C^{2}-0,1271 A B-46,5 A C-1,27 B C
\end{aligned}
$$

İkinci dereceden regresyon analizi sonucunda $\mathrm{R}^{2}$ \%98,78 olarak hesaplanmıştır. Çizelge 6'da yer alan $\mathrm{P}$ değerleri incelendiğinde; $\mathrm{A}, \mathrm{B}, \mathrm{B} * \mathrm{~B}$ ve $C^{*} C^{\prime}$ nin itme kuvveti üzerinde bir etkileri bulunmamaktadır. Çünkü $\mathrm{P}$ anlamlılık değerinin 0,05 'ten büyük olmasından dolayıdır.

Çizelge 6. İkinci dereceden regresyon analiz

\begin{tabular}{|c|c|c|c|c|}
\hline Term & Coef & $\begin{array}{c}\text { SE } \\
\text { Coef }\end{array}$ & $\begin{array}{c}\text { T- } \\
\text { Value }\end{array}$ & $\begin{array}{c}\text { P- } \\
\text { Value }\end{array}$ \\
\hline Constant & 20,81 & 6,79 & 3,06 & $\mathbf{0 , 0 0 7}$ \\
\hline $\mathrm{A}$ & $-0,39$ & 4,26 & $-0,09$ & 0,927 \\
\hline $\mathrm{B}$ & 0,044 & 0,120 & 0,37 & 0,715 \\
\hline $\mathrm{C}$ & 294,4 & 80,7 & 3,65 & 0,002 \\
\hline$A^{*} \mathrm{~A}$ & 6,48 & 2,59 & 2,50 & 0,023 \\
\hline $\mathrm{B} * \mathrm{~B}$ & 0,00049 & 0,00104 & 0,47 & 0,642 \\
\hline $\mathrm{C}^{*} \mathrm{C}$ & 147 & 259 & 0,57 & 0,577 \\
\hline$A * B$ & $-0,1271$ & 0,0366 & $-3,47$ & 0,003 \\
\hline $\mathrm{A}^{*} \mathrm{C}$ & $-46,5$ & 18,3 & $-2,54$ & 0,021 \\
\hline $\mathrm{B} * \mathrm{C}$ & $-1,270$ & 0,366 & $-3,47$ & 0,003 \\
\hline \multicolumn{5}{|c|}{ Model Özeti } \\
\hline & $\mathrm{R}^{2}:$ & \multicolumn{3}{|l|}{$\% 98,78$} \\
\hline & $\mathrm{R}^{2}$ (adj): & \multicolumn{3}{|l|}{$\% 98,14$} \\
\hline & $R^{2}$ (pred): & \multicolumn{3}{|l|}{$\% 96,83$} \\
\hline
\end{tabular}
katsayıları

\subsection{Tahminsel Sonuçların Karşılaştırılması}

Taguchi Metot, birinci ve ikinci dereceden regresyon analizleri sonucu tahmin edilen itme kuvveti Çizelge 7'de verilmiştir. Çizelge 7 incelendiğinde, tahmin modelleri ile deney sonuçları karşılaştırıldığında sırasıyla \% mutlak hata ve $\%$ ortalama mutlak hata değerleri hesaplanmıştır. İlk olarak, Taguchi Metodunda \% mutlak hata en fazla 7,46 iken en düşük 0,07 ve \% ortalama mutlak hata değeri 2,84 olarak belirlenmiştir. Ardından, birinci dereceden regresyon modelinde \% mutlak hata en fazla 6,80 iken en düşük 0,29 ve $\%$ ortalama mutlak hata değeri 3,28 olarak tespit edilmiştir. Son olarak, ikinci dereceden regresyon modelinde \% mutlak 
Kompozit Malzemeleri Delme Işsleminde İtme Kuvvetinin Taguchi Metodu ile Optimizasyonu ve Regresyon Analizi ile Tahmini

hata en fazla 4,31 iken en düşük 0,21 ve $\%$ hesaplanmıştır.

ortalama mutlak hata değeri 1,86 olarak

Çizelge 7. İtme kuvveti için Taguchi ve regresyon analizleri sonuçlarının karşılaştırılması

\begin{tabular}{|c|c|c|c|c|c|c|c|}
\hline Deney & $\begin{array}{l}\text { Deneysel } \\
\text { Fz (N) }\end{array}$ & $\begin{array}{l}\text { Taguchi } \\
\text { Tahmini }\end{array}$ & $\begin{array}{l}\text { \% Mutlak } \\
\text { Hata }\end{array}$ & $\begin{array}{l}\text { I. Dereceden } \\
\text { Regresyon }\end{array}$ & $\begin{array}{l}\text { \% Mutlak } \\
\text { Hata }\end{array}$ & $\begin{array}{l}\text { II. Dereceden } \\
\text { Regresyon }\end{array}$ & $\begin{array}{l}\text { \% Mutlak } \\
\text { Hata }\end{array}$ \\
\hline 1 & 50,66 & 54,31 & 7,20 & 53,54 & 5,69 & 49,97 & 1,37 \\
\hline 2 & 63,38 & 66,53 & 4,97 & 66,13 & 4,35 & 64,94 & 2,46 \\
\hline 3 & 82,56 & 79,49 & 3,72 & 78,73 & 4,64 & 80,65 & 2,31 \\
\hline 4 & 49,23 & 49,99 & 1,54 & 49,53 & 0,61 & 48,82 & 0,82 \\
\hline 5 & 61,94 & 62,21 & 0,44 & 62,12 & 0,29 & 62,21 & 0,44 \\
\hline 6 & 76,04 & 75,17 & 1,14 & 74,71 & 1,75 & 76,33 & 0,39 \\
\hline 7 & 46,30 & 46,28 & 0,04 & 45,52 & 1,69 & 48,29 & 4,31 \\
\hline 8 & 61,98 & 58,50 & 5,61 & 58,11 & 6,25 & 60,09 & 3,04 \\
\hline 9 & 71,86 & 71,46 & 0,56 & 70,70 & 1,62 & 72,63 & 1,07 \\
\hline 10 & 46,74 & 49,06 & 4,96 & 49,92 & 6,80 & 47,47 & 1,57 \\
\hline 11 & 62,95 & 61,29 & 2,64 & 62,51 & 0,70 & 61,29 & 2,64 \\
\hline 12 & 74,63 & 74,25 & 0,51 & 75,10 & 0,63 & 75,83 & 1,61 \\
\hline 13 & 44,43 & 44,74 & 0,70 & 45,90 & 3,32 & 44,74 & 0,70 \\
\hline 14 & 56,72 & 56,97 & 0,44 & 58,50 & 3,13 & 56,97 & 0,43 \\
\hline 15 & 67,20 & 69,93 & 4,06 & 71,09 & 5,78 & 69,93 & 4,06 \\
\hline 16 & 44,24 & 41,04 & 7,23 & 41,89 & 5,31 & 42,62 & 3,65 \\
\hline 17 & 54,18 & 53,26 & 1,70 & 54,48 & 0,56 & 53,26 & 1,70 \\
\hline 18 & 65,65 & 66,22 & 0,87 & 67,07 & 2,17 & 64,63 & 1,55 \\
\hline 19 & 48,33 & 47,06 & 2,63 & 46,29 & 4,22 & 48,22 & 0,22 \\
\hline 20 & 59,24 & 59,28 & 0,07 & 58,88 & 0,60 & 60,87 & 2,75 \\
\hline 21 & 75,01 & 72,24 & 3,69 & 71,48 & 4,71 & 74,25 & 1,01 \\
\hline 22 & 45,01 & 42,74 & 5,04 & 42,28 & 6,07 & 43,90 & 2,47 \\
\hline 23 & 55,86 & 54,96 & 1,61 & 54,87 & 1,77 & 54,96 & 1,61 \\
\hline 24 & 68,19 & 67,92 & 0,40 & 67,46 & 1,07 & 66,76 & 2,10 \\
\hline 25 & 39,30 & 39,03 & 0,69 & 38,27 & 2,63 & 40,19 & 2,27 \\
\hline 26 & 48,00 & 51,25 & 6,77 & 50,86 & 5,95 & 49,66 & 3,47 \\
\hline 27 & 59,75 & 64,21 & 7,46 & 63,45 & 6,19 & 59,87 & 0,21 \\
\hline \multicolumn{3}{|c|}{$\%$ Ortalama Mutlak Hata } & 2,84 & & 3,28 & & 1,86 \\
\hline
\end{tabular}

Bu bilgiler 1şı̆̆ında; en düşük \% ortalama mutlak hata değeri 1,86 ve en yüksek $\mathrm{R}^{2}$ değeri $(\% 98,78)$ ile en yüksek tahmin modeli ikinci dereceden regresyon olduğu tespit edilmiştir. Ardından, en düşük \% ortalama mutlak hata değeri 2,84 ve en yüksek $\mathrm{R}^{2}$ değeri $(\% 96,60)$ ile Taguchi metodu olduğu belirlenmiştir. Son olarak, en düşük \% ortalama mutlak hata değeri 3,28 ve en yüksek $\mathrm{R}^{2}$ değeri $(\% 96,11)$ ile birinci dereceden regresyon modelidir.
Genel olarak tahmin modelleri incelendiğinde her üç modelinde tahmin yeteneğinin güçlü olduğu görülmüştür. Belirtme katsayısının \%80 ila \%100 arasında olması durumunda modelin istatistiksel olarak anlamlı olduğunu göstermektedir [32].

Şekil 6 (a-c)'de deneysel sonuçlar ile tahmin modellerinden elde edilen değerlerin karşılaştırılması görülmektedir. Şekilde de görüldüğü gibi deney sonuçlarına en yakın tahmin modelinin ikinci dereceden regresyon modeli olduğu sonucuna varılmıştır. 


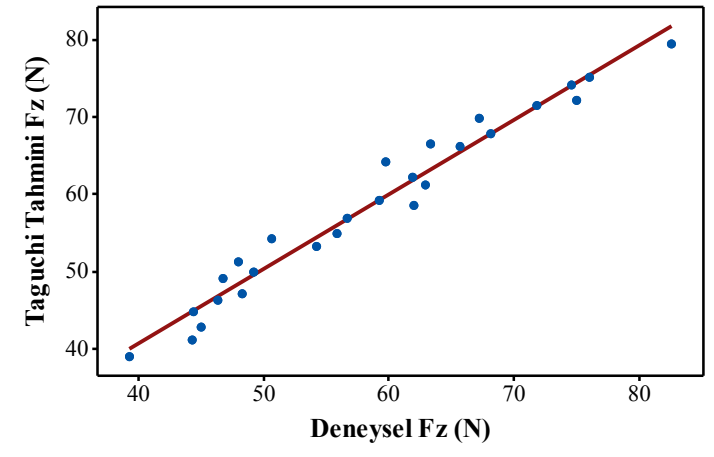

(a)

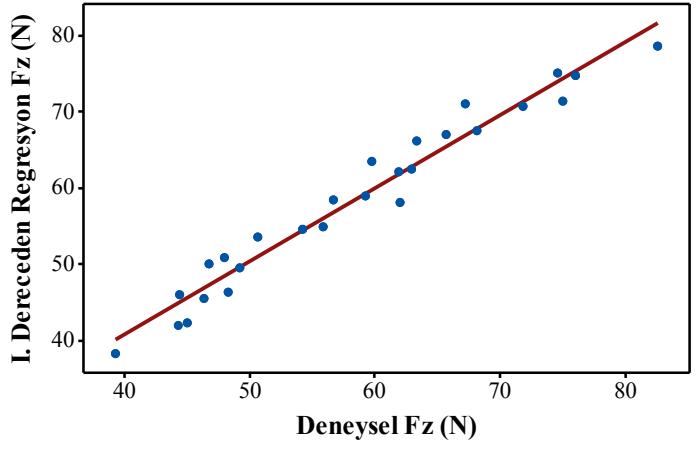

(b)

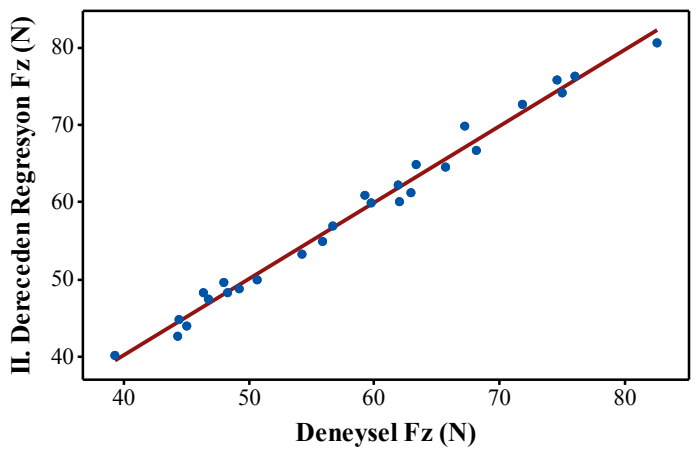

(c)

Şekil 6. İtme kuvveti için deneysel ve tahmini değerlerin kıyaslanması, a) Taguchi-deneysel, b) Birinci dereceden-deneysel, c) İkinci dereceden-deneysel

\section{SONUÇLAR}

$\mathrm{Bu}$ çalışmada, CEPT kompozit malzemesinin delme işleminde kullanılan faktör ve seviyelerin optimum koşulları Taguchi Metodu ile belirlenmiştir. Ağırlıkça \% ÇDKNT oranı, kesme hızı ve ilerlemenin itme kuvveti üzerindeki etki oranlarını tespit etmek için varyans analizi uygulanmıştır. Ayrıca, itme kuvvetinin tahmini için Taguchi, birinci ve ikinci dereceden regresyon modelleri oluşturulmuştur. Yapılan analizler ve hesaplamalar sonucunda elde edilen sonuçlar aşağıda maddeler halinde verilmiştir.

- Taguchi Metodu kullanılarak yapılan optimizasyon sonucunda en düşük itme kuvveti değeri için optimum delme parametreler, \% ÇDKNT oranı \%1, kesme hızı $75 \mathrm{~m} / \mathrm{dk}$ ve ilerleme $0,10 \mathrm{~mm} / \mathrm{dev}$ (A3B3C1) olarak tespit edilmiştir.

- Optimum delme parametreleri kullanılarak elde edilen en küçük itme kuvveti değeri 39,90 N olarak ölçülmüştür.

- İtme kuvvetinin ANOVA sonucuna göre, delme parametrelerinin itme kuvveti üzerindeki en etkili parametrenin \%81,17 ile ilerleme olduğu belirlenirken ardından sirasıyla \%8,26 ile kesme hızı ve \%7,18 ile \% ÇDKNT oranı olduğu tespit edilmiştir.

- İtme kuvveti ile delme parametreleri arasındaki etkileşime ilişkin yüzey grafikleri incelendiğinde, \% ÇDKNT oranı-kesme hızının artması ile itme kuvvetinde büyük ölçüde bir azalma görülmüştür. İlerleme-kesme 
hızı ve \% ÇDKNT oranı-ilerleme etkileşimlerinde ise ilerlemenin azalmasıyla itme kuvvetinde ciddi bir azalma meydana gelmiştir.

- Delme işlemleri sonunda oluşan itme kuvvetinin deneysel sonuçları ile Taguchi, birinci ve ikinci dereceden regresyon modellerin tahmin değerleri karşılaştırılmıştır. Karşılaştırma sonuçlarına göre en güçlü tahmin modeli, en yüksek belirtme katsayısı $\left(\mathrm{R}^{2}=\% 98,78\right)$ ve en düşük \% ortalama mutlak hataya $(\% 1,86)$ sahip olan ikinci dereceden regresyon modelidir.

- Tahmin modellerinin belirtme katsayıları oldukça yüksek değerlere sahip olup istatistiksel olarak anlamlı olduğu belirlenmiştir.

\section{TEŞEKKÜRLER}

Yazarlar, çalışmanın yürütülmesinde laboratuvar olanaklarını sunan Prof. Dr. İhsan KORKUT'a ve delme işlemi esnasındaki yardımlarından dolayı Arş. Gör. Bahattin YILMAZ'a teşekkür eder.

\section{KAYNAKLAR}

1. Kilıçkap, E., 2010. CETP Kompozitlerin Delinmesinde Oluşan Deformasyona Delme Parametrelerinin Etkisinin İncelenmesi, 2. Ulusal Tasarım İmalat ve Analiz Kongresi, Balıkesir, 76-84.

2. Bayraktar, Ş., Turgut, Y., 2012. Elyaf Takviyeli Polimer Kompozit Malzemelerin Delinmesi Üzerine Bir Araştırma, 3. Ulusal Talaşlı İmalat Sempozyumu, Ankara, 153-158.

3. Karaca, F., 2016. Cam Elyaf Takviyeli Plastik Kompozitlerde Delme Parametrelerinin Deformasyon Faktörüne Etkisinin Araştırılması, Fırat Üniversitesi Mühendislik Bilimleri Dergisi, 28(2), 23-27.

4. Mittal, G., Dhand, V., Rhee, K.Y., Park, S.J., Lee, W.R., 2015. A Review on Carbon Nanotubes and Graphene as Fillers in Reinforced Polymer Nanocomposites, Journal of Industrial and Engineering Chemistry, 21, $11-25$.
5. Advani, S.G., 2007. Processing and Properties of Nanocomposites, World Scientific Publishing, Singapore, 450.

6. Karimi, Z.N., Heidary, H., Yousefi, J., Sadeghi, S., Minak, G., 2018. Experimental Investigation on Delamination in Nanocomposite Drilling, FME Transactions, 46(1), 62-69.

7. Wern, C.W., Ramula, M., Schukla, A., 1996. Investigation of Stresses in the Orthogonal Cutting of Fiber-Reinforced Plastics, Experimental Mechanics, 36, 33-41.

8. Abrao, A.M., Faria, P.E., Rubio, J.C.C., Reis, P., Davim, J.P., 2007. Drilling of Reinforced Plastics: A Review, Journal of Materials Processing Technology, 186(1-3), 1-7.

9. Khashaba, U.A., 2004. Delamination in Drilling GFR-Thermoset Composites, Composite Structures, 63(3-4), 313-327.

10. Davim, J.P., Reis, P., 2003. Drilling Carbon Fiber Reinforced Plastics Manufactured by Autoclave-Experimental and Statistical Study, Materials \& Design, 24(5), 315-324.

11. Bilge, T., Motorcu, A.R., Ivanov, A., 2017. Kompakt Laminatın Delinmesinde Boyutsal Tamlık için Delme Parametrelerinin Gri İlişkisel Analiz ile Optimizasyonu, Uluslararası Teknolojik Bilimler Dergisi, 9(2), 1-22.

12. Davim, J.P., Reis, P., António, C.C., 2004. Experimental Study of Drilling Glass Fiber Reinforced Plastics (GFRP) Manufactured By Hand Lay-Up, Composites Science and Technology, 64(2), 289-297.

13. Saeedifar, M., Fotouhi, M., Ahmadi Najafabadi, M., 2016. Investigation of PushOut Delamination using Cohesive Zone Modelling and Acoustic Emission Technique. Journal of Composite Materials, 50(25), 3577-3588.

14. Unal, E., 2019. Temperature and Thrust Force Analysis on Drilling of Glass Fiber Reinforced Plastics. Thermal Science, 23(1), 347-352.

15. Singh, K. K., Kumar, D., 2018. Experimental Investigation and Modelling of Drilling on Multi-Wall Carbon Nanotube-Embedded Epoxy/Glass Fabric Polymeric Nanocomposites. Proceedings of the Institution of Mechanical Engineers, Part B:Journal of Engineering Manufacture, 232(11), 1943-1959. 
16. Vankanti, V. K., Ganta, V., 2014. Optimization of Process Parameters In Drilling Of GFRP Composite Using Taguchi Method. Journal of Materials Research and Technology, 3(1), $35-41$.

17. Vyas, N.S., Patel, A.R., Gajera, H.M., 2015. An Investigation on Thrust Force and Circularity of GFRP Sheet by Applying Regression Analysis. IJSRD, 3, 278-283.

18. Başar, G., Akın, H.K., Kahraman, F., 2020. Tepki Yüzeyi Metodolojisi Kullanılarak Nanokompozitin Delinmesinde oluşan İtme Kuvvetinin Modellenmesi ve Analizi, Gazi Üniversitesi Fen Bilimleri Dergisi Part C: Tasarım ve Teknoloji, 8(2), 293-305.

19. Yurdakul, M., Güneş, S., İç, Y.T., 2016. Honlama Prosesinde Yüzey Kalitesinin Taguchi Metodu ile İyileştirilmesi, Journal of the Faculty of Engineering \& Architecture of Gazi University, 31(2), 347-360.

20. İç, Y.T., Yıldırım, S., 2012. Çok Kriterli Karar Verme Yöntemleriyle Birlikte Taguchi Yöntemini Kullanarak Bir Ürünün Tasariminin Geliştirilmesi, Journal of the Faculty of Engineering and Architecture of Gazi University, 27(2), 447-458.

21. Başar, G., Mistıkoğlu, S., 2019. Cu/Al Levhaların Sürtünme Karıştırma Kaynağında Taguchi Metodu ile Çekme Mukavemeti ve Sertlik için Optimum Kaynak Parametrelerinin Tahmini, Journal of the Faculty of Engineering \& Architecture of Gazi University, 34(3), 1595-1608.

22. Gökçe, H., 2020. Bakır Malzemenin Delinme Performansının Kesme Kuvveti ve Takım Sıcaklığı Açısından İncelenmesi, El-Cezeri Journal of Science and Engineering, 7(3), 1039-1053.

23. Başar, G., Kahraman, F., Kuş, H., 2018. Bronz Esaslı Kompozit Sürtünme Malzemelerin Üç Nokta Eğme Mukavemetinin Taguchi Metodu ile Optimizasyonu, El-Cezeri Journal of Science and Engineering, 5(2), 626-634.

24. Ciftci, I., Gökçe, H., 2019. Molibden Alaşımlarının İşlenmesinde Kesici Takım ve Kesme Parametrelerinin Taguchi Metodu ile Optimizasyonu, Journal of the Faculty of Engineering and Architecture of Gazi University, 34(1), 201-213.
25. Başar, G., Kahraman, F., 2017. Delik İşleme Prosesinde Kesme Parametrelerinin Taguchi Metodu ve Regresyon Analizi Kullanılarak Modellenmesi ve Optimizasyonu, $2^{\text {nd }}$ International Mediterranean Science and Engineering Congress (IMSEC 2017), Adana, 688-695.

26. Basar, G., Kirli Akin, H., Kahraman, F., Fedai, Y., 2018. Modeling and Optimization of Face Milling Process Parameters for AISI 4140 Steel, Tehnički glasnik, 12(1), 5-10.

27. Fedai, Y., Ünüvar, A., Akın, H.K., Başar, G., 2019. 316L Paslanmaz Çeliklerin Frezeleme İşlemindeki Yüzey Pürüzlülüğün ANFIS ile Modellenmesi, Düzce Üniversitesi Bilim ve Teknoloji Dergisi, 7(2), 98-110.

28. Tsao, C.C., Huang, C.C., 2015. Analysis of Thrust-İnduced Drilling in Composite Materials using a Hemispherical Drill, The International Journal of Advanced Manufacturing Technology, 80(1-4), 607-613.

29. Premnath, A.A., 2019. Drilling Studies on Carbon Fiber-Reinforced Nano-Sic Particles Composites using Response Surface Methodology, Particulate Science and Technology, 37(4), 478-486.

30. Palanikumar, K., 2011. Experimental investigation and Optimisation in Drilling of GFRP Composites, Measurement, 44(10), 2138-2148.

31. Kumar, D., Singh, K.K., 2019. Investigation of Delamination and Surface Quality of Machined Holes in Drilling of Multiwalled Carbon Nanotube Doped Epoxy/carbon Fiber Reinforced Polymer Nanocomposite, Proceedings of the Institution of Mechanical Engineers, Part L: Journal of Materials: Design and Applications, 233(4), 647-663.

32. Kus, H., Basar, G., Kahraman, F. 2018. Modeling and Optimization for Fly Ash Reinforced Bronze-Based Composite Materials using Multi Objective Taguchi Technique and Regression Analysis, Industrial Lubrication and Tribology, 70(7), 1187-1192. 
